suicide. Among the 234 respondents on ART, median treatment duration was 24 (IOR: 9-39) months. Individuals being treated with ART for 2 years or less were more likely than those not using ART both to register depression on the $\mathrm{BDI}(\mathrm{AOR}=2.57,95 \% \mathrm{CI}$ : 1.08-6.11) and to report suicidal ideation ( $\mathrm{AOR}=4.08,95 \% \mathrm{CI}$ : 1.29-12.85). A history of attempting suicide was correlated with being on ART for more than 2 years (AOR $=3.98,95 \%$ CI: $1.38-11.48$ ).

Conclusion Our study shows that PLWHA treated with ART are more likely to experience depressive symptoms, particularly in the earlier treatment stages. This suggests a critical need for psychological support alongside initiation of treatment. Further work to identify specific patterns and causes of these symptoms and effective ways of managing them is recommended.

\section{P4.150 ELEMENTS OF THE ISEAN-HIVOS MONITORING AND EVALUATION TOOLKIT- RESPONDING TO THE CHALLENGE OF QUALITY MGE SYSTEMS IMPLEMENTATION IN A REGIONAL HIV-PROGRAM CONTEXT}

doi:10.1136/sextrans-2013-051184.1045

\begin{abstract}
A Lesmana. Hivos, Jakarta, Indonesia
\end{abstract}
Introduction In 2010, to address the increased vulnerability of MSMs as well as Transgenders to HIV transmission especially in the context of South East Asia, ISEAN and Hivos, jointly submitted a regional proposal to the Global Fund Round 10. The programme's goal is to reduce the vulnerability and risks of MSM and TG to HIV infection in the island countries of Southeast Asia. This grant was approved and has since then been called, the ISEAN Hivos Program. Part of the challenge of implementing a regional programme is being able to fulfil its monitoring and evaluation requirements. In the initial phase of the ISEAN-Hivos implementation, efforts were undertaken to manualize the Programs M\&E Requirements leading to the development of an M\&E Toolkit.

Methods This presentation provides a description of the ISEANHivos Toolkit and shares the principles that it followed to come up with a tool that can be applied in implementing an HIV-prevention project, targeting MSMs and TGs in Indonesia, Malaysia, Philippines and Timor Leste. The ISEAN-Hivos M\&E Toolkit is comprised of the following:

1. Approved M\&E Plan and Performance Framework

2. M\&E Reporting Templates and Tools

3. Unique Identifying Code Guidelines

4. ISEAN Hivos Calendar for Reporting

Conclusion The experience of ISEAN-Hivos in fielding its M\&E Toolkit provides empirical evidence of the value of manualization of programme management tools and guidelines in coordinating a cross-country regional HIV grant, which can provide learning for similar initiatives in various geographical contexts.

\section{P4.151 OVC STATUS AS PREDICTOR OF POOR OUTCOMES IN CHILDREN; COMBINATION OF HOUSEHOLD POVERTY AND CARING FOR OVC HAS WORSE CHILD OUTCOMES}

doi:10.1136/sextrans-2013-051184.1046

\section{G Biemba. Boston University, Boston, MA, United States}

According to scientific literature there are various markers of child vulnerability. Among them are: household wealth status, education levels of caregivers, living arrangements, relationship to head of household, Orphanhood, and OVC status. This paper examines specifically the role of orphanhood and OVC status in predicting child outcome in health, education, access to food and nutritional status. The study was conducted in the districts of Marracuene, Katembe, Dondo, and the administrative post of Natikire in Mozambique. We conducted a household survey of 1,759 households with 5,726 children aged 0-17years. This Abstract focuses on children under the age five years only. We examined shelter, health, food security and nutrition, legal protection, education, and psychosocial outcomes among children and we measured differences in these outcomes based on whether households care for OVC and on poverty status. We disaggregated household level data in order to show the differences between (1) poor households taking care of OVC, (2) poor households not taking care of OVC, (3) non-poor households with OVC, and (4) non-poor households without OVC. This categorization allows us to demonstrate disparities among households and highlights the most vulnerable households.

OVC status was found to be an independent predictor of poor child outcomes in terms of food security, nutritional status, health, psychosocial wellbeing, and education. For example, among children under five years old, poor OVC households were more than twice as likely to have a child go hungry a day and night compared to poor non-OVC households. Among 5-11 year olds, poor OVC were more likely to be behind in grade-for-age compared to poor non-OVC and more than twice as likely compared to non-poor, non-OVC. In logistic regression models, poor OVC were 2.7 times more likely to be out of school compared to non-poor, non-OVC.

\section{P4.152 ASSOCIATION OF SEXUAL BEHAVIOURS, CONDOM USE AND HISTORY OF SEXUALLY TRANSMITTED INFECTIONS AMONG MEDICAL STUDENTS IN CANTON SARAJEVO}

doi:10.1136/sextrans-2013-051184.1047

'S Mahmutovic Vranic, ${ }^{1} \mathrm{E}$ Ademovic, ${ }^{2} \mathrm{M}$ Seremet. ${ }^{1}$ School of Medicine, University of Sarajevo, Sarajevo, Bosnia and Herzegovina; ${ }^{2 K C U S}$, Sarajevo, Bosnia and Herzegovina

Introduction Sexually transmitted infections (STIs) have become a leading global public healthcare problem. The aim of the study was to determine and evaluate certain aspects of sexual behaviours among medical students in Sarajevo.

Methods The two parts of the survey were cross-sectional analysed among 188 and 220 students by means of valid self - reported questionnaires in 2011/2012 and 2012/2013 at University of Sarajevo, BaH. Results In the first part of the survey a total of 188 students were observed, out of which in the group 18-21 of age $-35.3 \%$ males and $64.7 \%$ females and in the group of $22-25$ of age $-50.9 \%$ males and $49.1 \%$ females, respectively. Sexual experiance have had $67.5 \%$ of students, out of which at the age of $\leq 16-86.9 \%$ males and $13.1 \%$ females, while at the age of $\geq 17-46.1 \%$ males and $53.69 \%$ females. In the last 12 months $56.9 \%$ males used condom each time during sexual intercourse as well as $41.5 \%$ females. In the second part of the survey a total of 220 students were observed, out of which in the group $18-21$ of age- $31.4 \%$ males and $68.6 \%$ females; in the group of $22-25$ of age- $40.5 \%$ males and $59.5 \%$ females; in the third group $\geq 26$ of age- $46.0 \%$ males and $54.0 \%$ females. Sexual experiance have had $53.6 \%$ of students, out of which at the age of $\leq 16-94.7 \%$ males and $0.53 \%$ females, while at the age of $\geq 17-47.5 \%$ males and $52.5 \%$ females, respectively. In the last 12 months $33.8 \%$ males used condom each time during sexual intercourse as well as $30.2 \%$ females. There was not a significant difference in condom use in relation to students knowledge about STIs (p0.05).

Conclusions Health education of youth improves their knowledge of sexual behaviour, provides support and develops skills needed for avoiding risk-taking behaviour, as well as preventing major STIs.

\section{P.05 - Translational and Implementation Sciences Track}

\section{P5.001 THE EFFECT OF ADVANCED PARTNER NOTIFICATION FOR} PEOPLE LIVING WITH HIV AND AIDS

doi:10.1136/sextrans-2013-051184.1048 